\title{
Recovery of iron from copper tailings via low-temperature direct reduction and magnetic separation: process optimization and mineralogical study
}

\author{
Rui-min Jiao, Peng Xing, Cheng-yan Wang, Bao-zhong Ma, and Yong-Qiang Chen \\ School of Metallurgical and Ecological Engineering, University of Science and Technology Beijing, Beijing 100083, China \\ (Received: 6 April 2017; revised: 5 May 2017; accepted: 31 May 2017)
}

\begin{abstract}
Currently, the majority of copper tailings are not effectively developed. Worldwide, large amounts of copper tailings generated from copper production are continuously dumped, posing a potential environmental threat. Herein, the recovery of iron from copper tailings via low-temperature direct reduction and magnetic separation was conducted; process optimization was carried out, and the corresponding mineralogy was investigated. The reduction time, reduction temperature, reducing agent (coal), calcium chloride additive, grinding time, and magnetic field intensity were examined for process optimization. Mineralogical analyses of the sample, reduced pellets, and magnetic concentrate under various conditions were performed by X-ray diffraction, optical microscopy, and scanning electron microscopy-energy-dispersive X-ray spectrometry to elucidate the iron reduction and growth mechanisms. The results indicated that the optimum parameters of iron recovery include a reduction temperature of $1150^{\circ} \mathrm{C}$, a reduction time of $120 \mathrm{~min}$, a coal dosage of $25 \%$, a calcium chloride dosage of $2.5 \%$, a magnetic field intensity of $100 \mathrm{mT}$, and a grinding time of $1 \mathrm{~min}$. Under these conditions, the iron grade in the magnetic concentrate was greater than $90 \%$, with an iron recovery ratio greater than $95 \%$.
\end{abstract}

Keywords: copper tailings; iron; direct reduction; magnetic separation; recovery; process optimization

\section{Introduction}

Approximately 30 million tons of copper slag is annually produced worldwide [1], for China, the leading producer of copper, accounting for nearly one-third of the total [2]. Slag contains various valuable metals, e.g., copper, zinc, cobalt, and nickel, and a small amount of precious metals; in addition, the iron content in slag is significantly greater than the mining grade of several iron mines [3-4]. Currently, in addition to being a copper source, slag is directly used as an abrasive grit [5-6] in cement and concrete materials [7-9], most of which are discarded after the cleaning of copper. Copper, zinc, cobalt, and nickel are the primary metals recovered, and several cleaning methods (e.g., pyrometallurgical slag settling or reduction or reductive sulfidizing) and the processing of slag minerals have been used to recover copper and other valuable metals from copper slag [10-14]. However, currently, the bulk iron in copper slag is not effectively re- covered on an industrial scale, leading to considerable waste of iron resources.

In recent years, considerable research efforts have been devoted to the recovery of iron from copper tailings. Because the iron in copper slag mainly exists as fayalite $\left(\mathrm{Fe}_{2} \mathrm{SiO}_{4}\right)$ and extremely fine grains of magnetite $\left(\mathrm{Fe}_{3} \mathrm{O}_{4}\right)$, it is difficult to effectively recover by conventional mineral processing technology [15-18]. Zhang et al. [19] have studied the conversion of the iron-bearing phases in copper slag into magnetite via the oxidation of molten slag with air or oxygen. The concentration of magnetite in the slag is increased from $22 \%$ to greater than $85 \%$ by this method, which is beneficial for the recovery of iron by magnetic separation. However, this process is complex, and the magnetic slag requires further treatment for recovering iron. Some studies [20-21] have reported the smelting reduction ironmaking of copper slag. Although a considerable recovery was achieved on the laboratory scale because of the high $\mathrm{Si} / \mathrm{Fe}$ ratio, the feasibility of such processing on 
the industrial scale requires further examination. Numerous laboratory-scale studies have focused on the reduction and magnetic separation of copper slags [22-24]. A high recovery ratio and grade of iron in the concentrate can typically be attained using this method, and the reduced iron concentrate can be used as a high-quality raw material for steelmaking. However, the high reduction temperature $\left(1200-1300^{\circ} \mathrm{C}\right)$ adopted in these studies can easily lead to sintering, which would be detrimental during the processing of copper tailings in industrial facilities, e.g., in a rotary kiln. Furthermore, because most of these tests were conducted under nitrogen, oxidation of the reduced product under atmospheric conditions was not considered. In addition, the authors of previous studies did not thoroughly examine the mechanism of iron reduction. In this context, the low-temperature reduction of pellets of depleted copper tailings was proposed herein, and the process optimization and the reduction mechanism were investigated.

\section{Experimental}

\subsection{Materials}

In this study, the copper tailing sample was collected from a waste copper tailing stockpile of a dressing plant in a copper smelter. This sample was dried at $60^{\circ} \mathrm{C}$ for $12 \mathrm{~h}$ and subsequently analyzed by inductively coupled plasma-atomic emission spectroscopy (ICP-AES). The sulfur content was analyzed using an infrared absorption car- bon-sulfur analyzer. Table 1 summarizes the chemical composition of the sample. The elemental composition was dominated by $\mathrm{Fe}, \mathrm{Ca}$, and $\mathrm{SiO}_{2}$. The results obtained from the size analysis of the initial ore and the content analysis of $\mathrm{Fe}$ in different fractions $(0.149-0.074,0.074-0.048$, and $-0.048 \mathrm{~mm}$ ) suggest that the primary particle size of the tailing sample was less than $0.048 \mathrm{~mm}$, albeit with an almost equal iron content in each fraction. Lignite coal with $52.1 \mathrm{wt} \%$ fixed carbon and $28.3 \mathrm{wt} \%$ volatile matter was used in reduction experiments. Analytical reagent (AR)-grade calcium chloride was used as an additive.

\subsection{Experimental method}

First, the original sample (100 g) was mixed with various proportions of pulverized coal and calcium chloride. Second, $20 \mathrm{~mL}$ of water was added to the mixture, which was subsequently pelletized. Third, the pellets were placed in an oven at $110^{\circ} \mathrm{C}$ for drying. The pellets were then placed in a crucible with a sealed cover and reduced in a muffle furnace (TDW, Tianjin Zhonghuan Lab Furnace Co. Ltd., China) at a predefined temperature. Finally, the reduced samples were rapidly removed and quenched with water. The partially reduced pellets were wet-ground (5:1 liquid-solid ratio (v/w)) in a rod mill (XZM-100, Wuhan Exploring Machinery Factory, China) and then magnetically separated using a magnetic separator (DTCXG-ZN50, Tangshan Dongtang Electric Equipment Co. Ltd., China) to obtain the iron concentrate. The remaining pellets were dried for mineralogical analysis.

Table 1. Chemical composition of the copper tailing sample

\begin{tabular}{cccccccccccccc}
\hline $\mathrm{Fe}$ & $\mathrm{Ca}$ & $\mathrm{Zn}$ & $\mathrm{Al}$ & $\mathrm{Mg}$ & $\mathrm{Pb}$ & $\mathrm{Cu}$ & $\mathrm{Ti}$ & $\mathrm{Ba}$ & $\mathrm{S}$ & $\mathrm{P}$ & $\mathrm{Si}$ \\
\hline 41.19 & 12.87 & 3.79 & 2.28 & 1.01 & 0.47 & 0.38 & 0.25 & 0.15 & 0.13 & 0.01 & 11.88 \\
\hline
\end{tabular}

\subsection{Experimental principle}

The copper slag mainly contains ferrite (magnetite) and fayalite. Fayalite typically dissociates into $\mathrm{FeO}$, followed by reduction to metallic iron [22], as shown in Eq. (1). Eqs. (2)-(4) show the reduction of iron oxides $\left(\mathrm{FeO}, \mathrm{Fe}_{2} \mathrm{O}_{3}\right.$, and $\mathrm{Fe}_{3} \mathrm{O}_{4}$, respectively) by carbon. Fig. 1 shows the standard Gibbs energy of these iron oxides vs. temperature. The initiation temperatures of the reactions shown in Eqs. (2)-(4) at atmospheric pressure were calculated as 718,299 , and $681^{\circ} \mathrm{C}$, respectively.

$$
\begin{aligned}
& \mathrm{Fe}_{2} \mathrm{SiO}_{4}(\mathrm{~s})=2 \mathrm{FeO}(\mathrm{s})+\mathrm{SiO}_{2}(\mathrm{~s}) \\
& \mathrm{FeO}(\mathrm{s})+\mathrm{C}(\mathrm{s})=\mathrm{Fe}+\mathrm{CO}(\mathrm{g}) \\
& 3 \mathrm{Fe}_{2} \mathrm{O}_{3}(\mathrm{~s})+\mathrm{C}(\mathrm{s})=2 \mathrm{Fe}_{3} \mathrm{O}_{4}(\mathrm{~s})+\mathrm{CO}(\mathrm{g})
\end{aligned}
$$

$\mathrm{Fe}_{3} \mathrm{O}_{4}(\mathrm{~s})+\mathrm{C}(\mathrm{s})=3 \mathrm{FeO}(\mathrm{s})+\mathrm{CO}(\mathrm{g})$

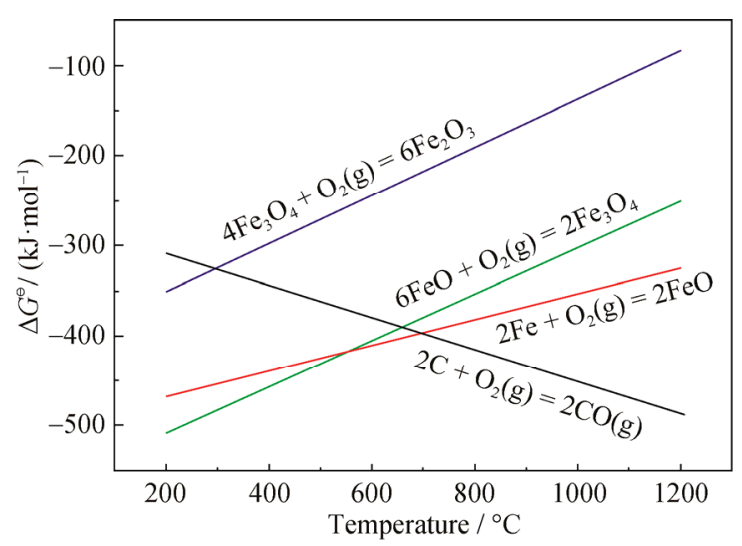

Fig. 1. Standard Gibbs free energy $\left(\Delta G^{\ominus}\right)$ of several oxides. 


\section{Results and discussion}

\subsection{Direct reduction and magnetic separation}

Fig. 2(a) shows the effect of reduction temperature (800, $900,1000,1100,1150$, or $1200^{\circ} \mathrm{C}$ ) on the recovery and
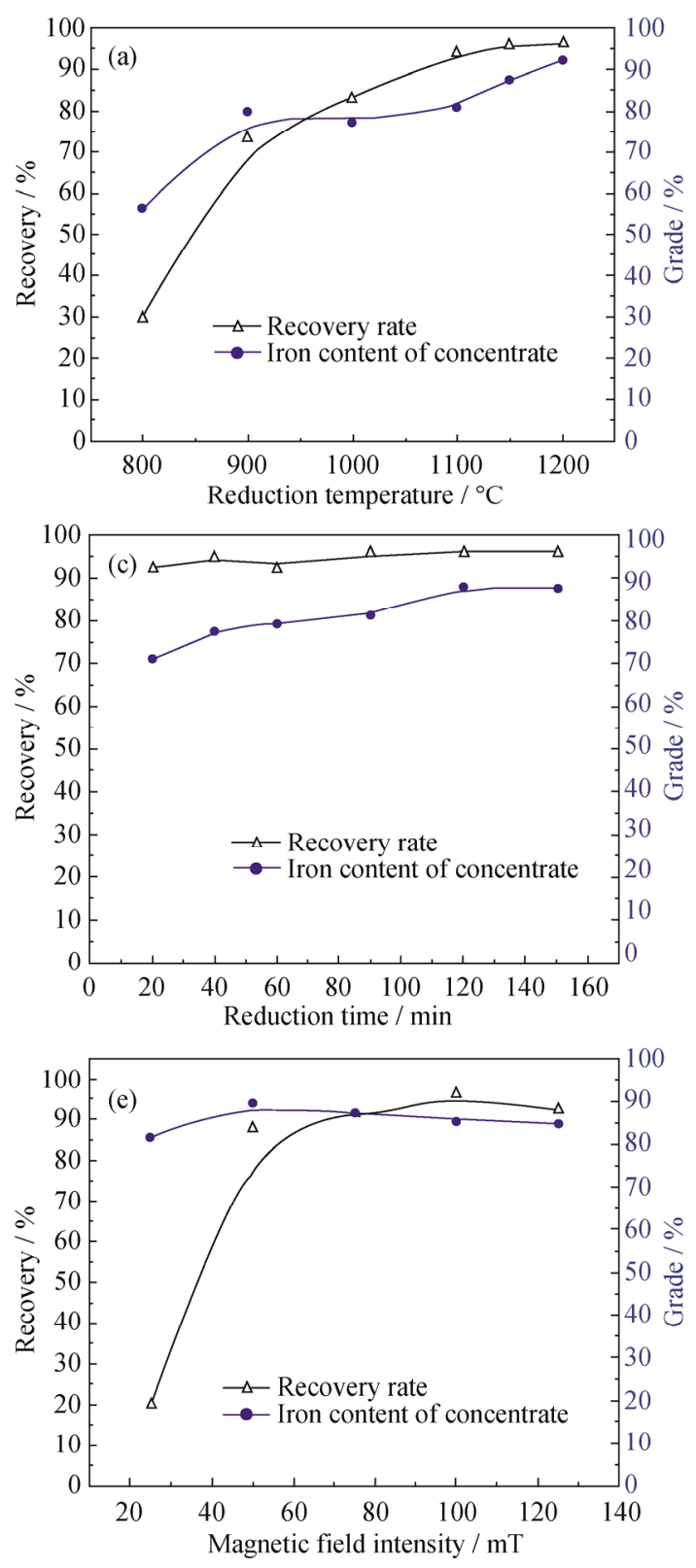

grade of iron in the concentrate. The recovery ratio and iron grade in the concentrate increased with increasing reduction temperature (Fig. 2(a)). The recovery ratio reached a plateau at $1150^{\circ} \mathrm{C}$, whereas the maximum iron grade was achieved at $1200^{\circ} \mathrm{C}$.
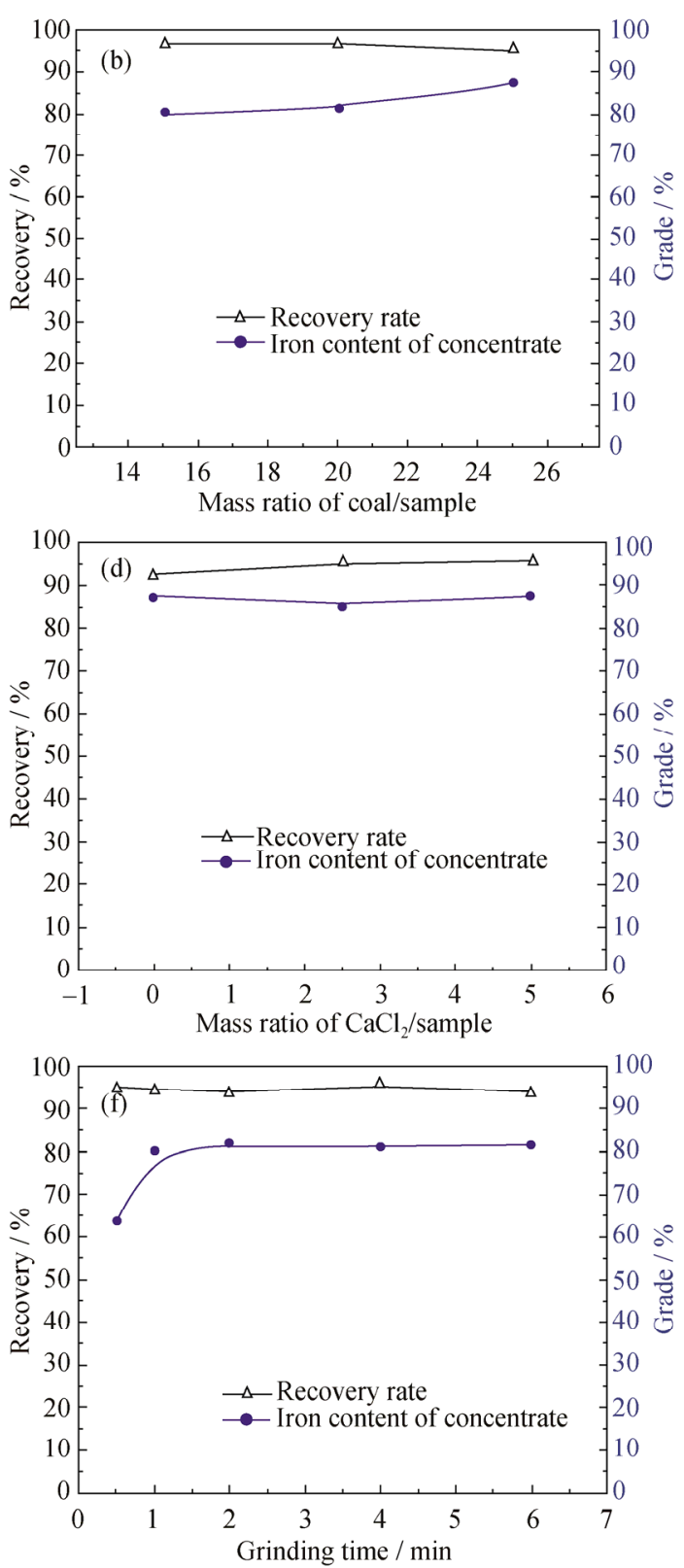

Fig. 2. Effects of reduction conditions on the recovery and grade of iron in the concentrate: (a) reduction temperature; (b) coal; (c) reduction time; (d) $\mathrm{CaCl}_{2}$; (e) magnetic field intensity; (f) grinding time (In addition to the corresponding variables shown in the figures, other experimental conditions were as follows: reduction temperature, $1150^{\circ} \mathrm{C}$; mass ratio of coal/sample, $25 \%$; reduction time, $2 \mathrm{~h}$; mass ratio of $\mathrm{CaCl}_{2} / \mathrm{sample}, 2.5 \%$; grinding time, $4 \mathrm{~min}$; magnetic field intensity, $100 \mathrm{mT}$ ).

Fig. 3 shows the photographs of the samples reduced at different temperatures. The pellets reduced at $1150^{\circ} \mathrm{C}$ exhibited excellent physical and mechanical properties, e.g., a dense surface, good strength, and high antioxidant capacity (Fig. 3). However, with the further increase of temperature $\left(1200^{\circ} \mathrm{C}\right)$, the reduced pellets were sintered and became semi-molten, which is detrimental to stable operation in industrial settings. For instance, in the case of a rotary kiln, which is a common piece of equipment for reduction of metals such as nickel and iron, the sintered material easily 
adhered to the rotary kiln wall, possibly leading to difficulty in the smooth passage of the reduced material. In addition to this issue, after the samples were quenched with water, the
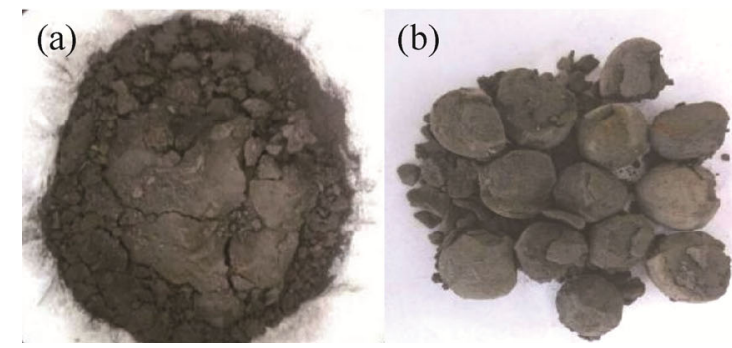

sample reduced at $1200^{\circ} \mathrm{C}$ was easily oxidized in the environment. On the basis of these findings, the optimum temperature for reduction was determined to be $1150^{\circ} \mathrm{C}$.

(c)

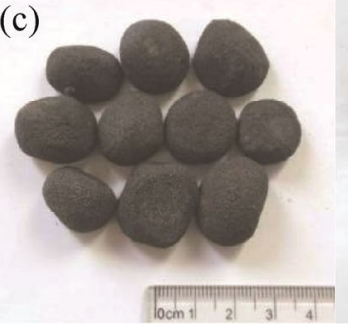

(d)

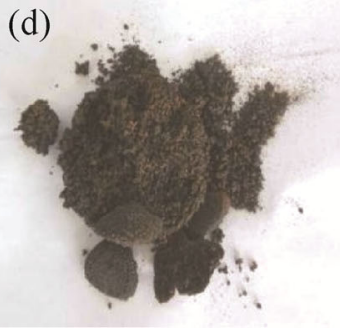

Fig. 3. Photographs of the pellets reduced at different temperatures: (a) $900^{\circ} \mathrm{C}$; (b) $1000^{\circ} \mathrm{C}$; (c) $1150^{\circ} \mathrm{C} ;$ (d) $1200^{\circ} \mathrm{C}$.

The effect of coal dosage on reduction was investigated at the mass ratios of coal:sample of $15 \%-25 \%$ (according to the carbon content of the coal and the reaction $\mathrm{FeO}+\mathrm{C} \rightleftharpoons$ $\mathrm{Fe}+\mathrm{CO}, 15 \%$ of the coal amount was 0.9 times the theoretical amount). The recovery ratio was slightly affected by the coal dosage; however, the concentration of iron grade increased with increasing reducing-agent dosage; hence, the optimum reducing-agent dosage was $25 \%$.

Fig. 2(c) shows the effect of reduction time on the recovery and grade of iron. The grade of iron in the concentrate increased with increasing reduction time and reached a plateau at $120 \mathrm{~min}$, whereas the recovery was barely affected. The appropriate reduction time to ensure a high concentrate grade was determined to be $120 \mathrm{~min}$.

Chlorides have been reported to be beneficial for the extraction of certain metals, e.g., nickel and lithium, from minerals in the presence of silica because of the chloride segregation effect [25-26]. Hence, we introduced calcium chloride. Fig. 2(d) shows the effect of the mass ratio of $\mathrm{CaCl}_{2}$ :sample on the recovery and grade of iron. The calcium chloride was not found to affect the recovery and grade of iron. However, the addition of calcium chloride was beneficial to pelletization; hence, the optimum calcium chloride dosage was determined to be $2.5 \%$.

Fig. 2(e) shows the effect of the magnetic field intensity on the recovery and grade of iron. The recovery of iron rapidly increased with increasing magnetic field intensity and reached a plateau at $100 \mathrm{mT}$. The magnetic field intensity marginally affected the grade of iron in the concentrate. A high magnetic field intensity $(100 \mathrm{mT})$ was imperative for iron recovery.

Fig. 2(f) shows the effect of grinding time on the recovery and grade of iron. In only $1 \mathrm{~min}$, the grade of iron in the concentrate reached a plateau, which was reasonable because the reduced pellet could be easily ground; all particle sizes were less than 300 mesh. When the grinding time was insufficient, iron was not easily dissociated, resulting in a low grade of iron in the concentrate; hence, the optimum grinding time was $1 \mathrm{~min}$.

On the basis of the aforementioned single-factor experiments, an integrated experiment was conducted. The following optimized leaching conditions were selected: a reduction temperature of $1150^{\circ} \mathrm{C}$, a reduction time of $2 \mathrm{~h}$, a coal:sample mass ratio of $25 \%$, a $\mathrm{CaCl}_{2}$ :sample mass ratio of $2.5 \%$, a magnetic field intensity of $100 \mathrm{mT}$, and a grinding time of $1 \mathrm{~min}$. Under such conditions, a recovery of $95.86 \%$ and an iron grade of $90.2 \%$ were obtained, with the content of iron in the tailing being only $4.78 \mathrm{wt} \%$.

\subsection{Mineralogical study of reduction}

\subsubsection{Characterization of the raw material}

X-ray diffraction (XRD), optical microscopy, and scanning electron microscopy-energy-dispersive X-ray spectrometry (SEM-EDS) were used to analyze the copper tailing. Figs. 4-7 show the corresponding results.

The XRD patterns indicate that the main phases in the copper tailing were ferrite (magnetite), fayalite, hedenbergite, and a small amount of calcite. In the representative optical microscopy image of the raw material, the multi-granularity of ferrite (Frr) and fayalite $(\mathrm{Fa})$ phases varies from 10 to $100 \mu \mathrm{m}$.

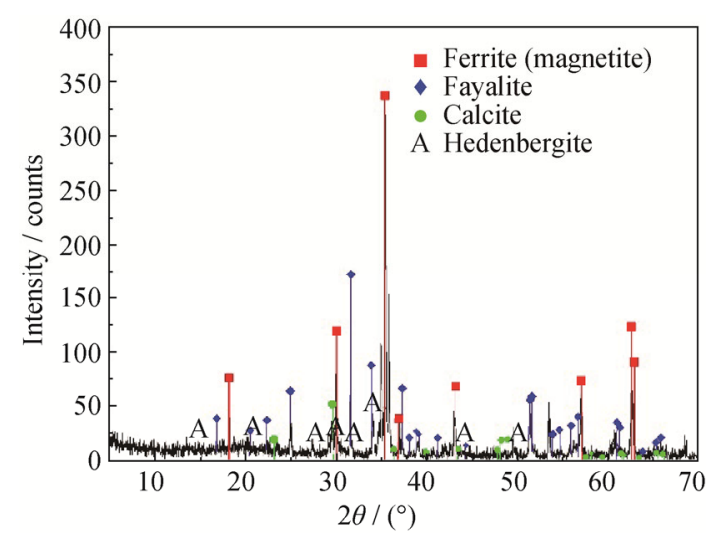

Fig. 4. XRD pattern of the copper tailing. 

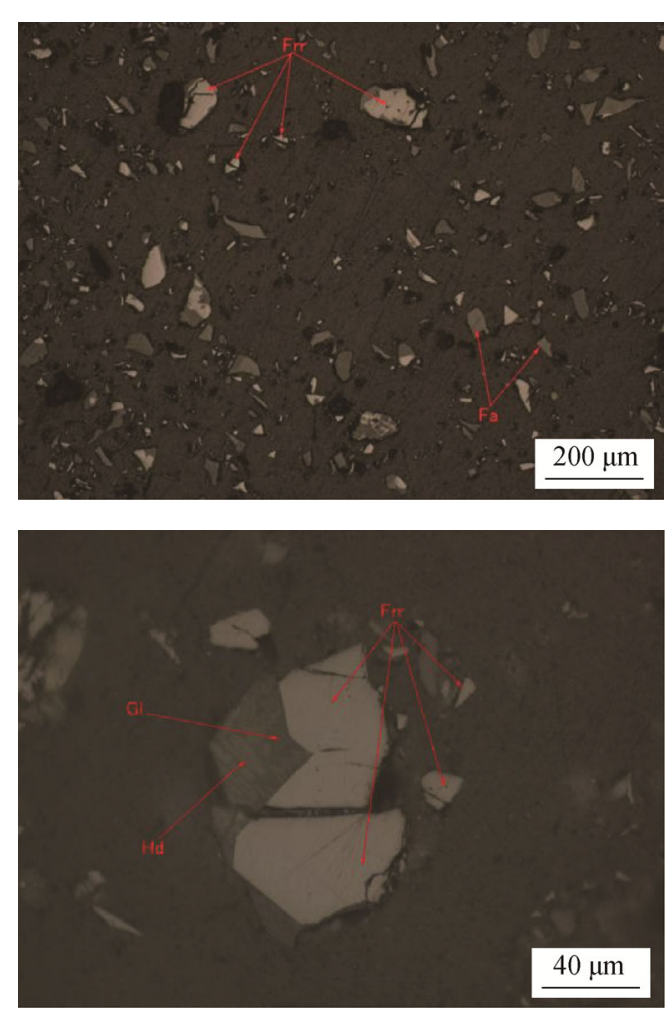

Fig. 5. Representative optical microscope image of the copper tailing. Frr-ferrite; Fa-fayalite; Hd-hedenbergite; Gl一glass.
The copper tailing contained ferrite, fayalite, hedenbergite, and silicate glass, with a marginal amount of matte particles (Fig. 4). The SEM-EDS results also indicate that the main phases of the copper tailing included ferrite and fayalite, which initially precipitated during slow cooling; hence, their crystal sizes are large. Later, hedenbergite precipitated as dendrites.

\subsubsection{Characterization of the reduced pellet}

Fig. 7 shows the optical microscopy images of the pellets reduced at different temperatures. Although the reduction of

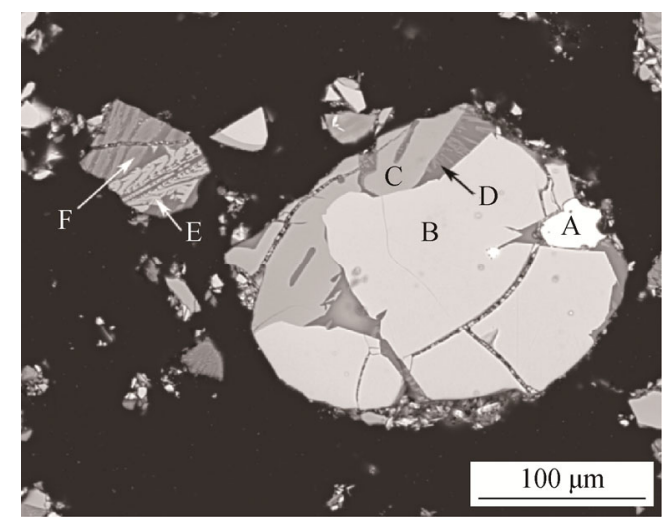

Fig. 6. Representative SEM-EDS patterns of the copper tailing. A-matte; $\mathrm{B}$-ferrite; $\mathrm{C}$-fayalite; $\mathrm{D}$-glass; $\mathrm{E}$-fayalite; F-hedenbergite.
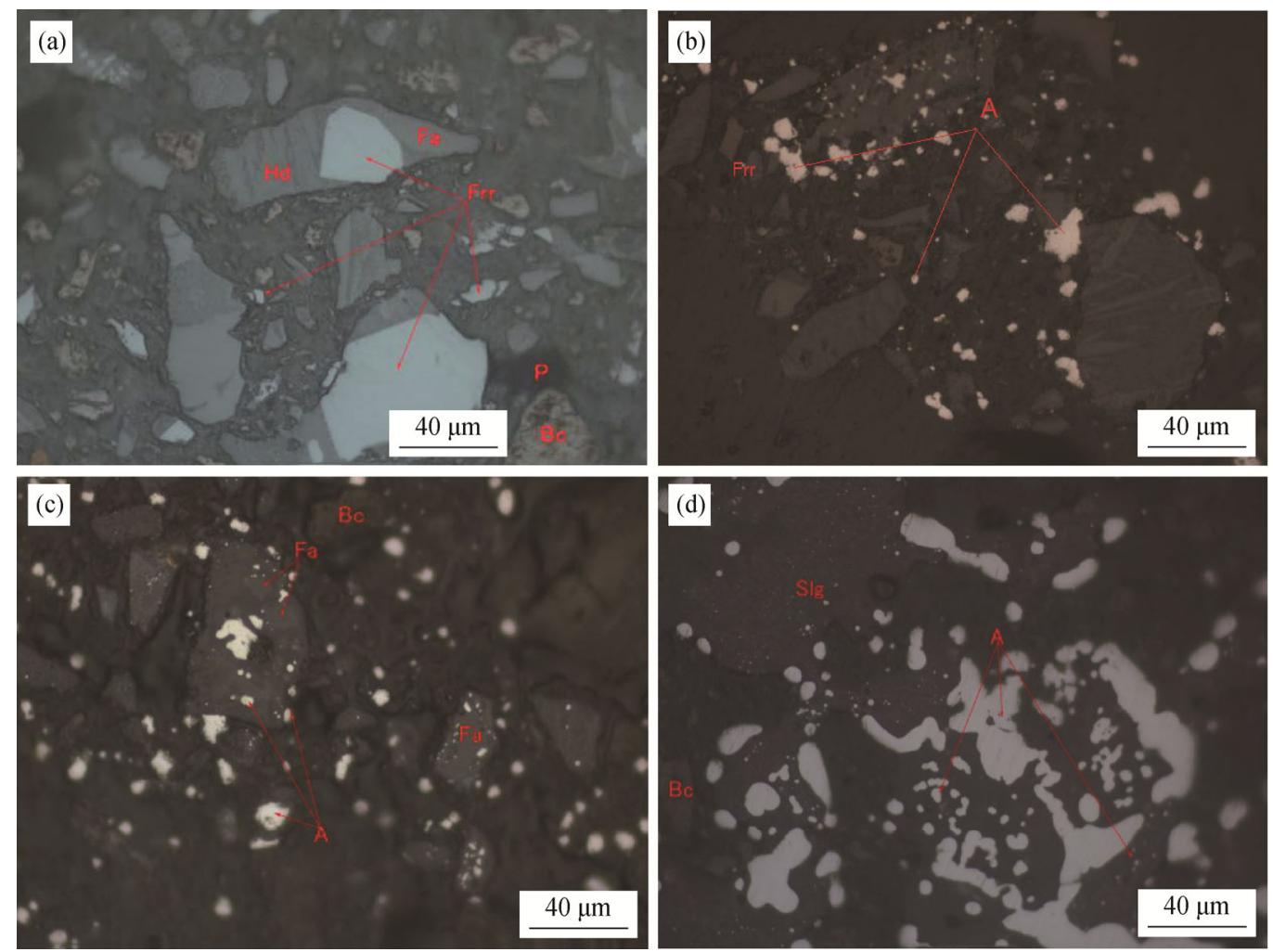

Fig. 7. Optical microscopy images of pellets reduced at different temperatures: (a) $800^{\circ} \mathrm{C}$; (b) $900^{\circ} \mathrm{C} ;\left(\right.$ c) $1000^{\circ} \mathrm{C}$; (d) $1150^{\circ} \mathrm{C}$. A—metallic phase; Bc—black charcoal; Frr—ferrite; Fa—fayalite; P—pore; Slg—slag; Hd—hedenbergite. 
$\mathrm{FeO}$ can theoretically occur at $800^{\circ} \mathrm{C}$ (Fig. 2), the ferrite and fayalite in the pellets were not reduced and the coal particle shape was also maintained at this temperature (Fig. 7) because carbon failed to react with oxygen to form a strong reducing atmosphere in the actual test environment even though carbon could theoretically react with oxygen. A small amount of metallic iron was observed in the pellet reduced at $900^{\circ} \mathrm{C}$. Hence, the merging of metallic iron was not observed, and fine particles $(<20 \mu \mathrm{m})$ of the metal phase were observed. Isolated ferrite with a small particle size is thought to be reduced to metal at this temperature; however, because the low-melting liquid and binding phases, which strongly affected pellet consolidation, were not formed, low pellet strength was observed and the metallic phase particles did not grow.

During reduction at $1150^{\circ} \mathrm{C}$, a majority of the iron was reduced to the metal state, which merged as irregular granules and beads. The structure of the reduced pellet obtained at $1150^{\circ} \mathrm{C}$ differed substantially from that of the pellet reduced at $1000^{\circ} \mathrm{C}$. Specifically, the pores of the pellet reduced at $1150^{\circ} \mathrm{C}$ were smaller, and the pellet exhibited a substantially increased density. The presence of residual coal particles in the pellet reduced at $1150^{\circ} \mathrm{C}$ indicates that the reducing-agent dosage was sufficient for iron reduction.

In addition, metal particles of the pellets reduced at high temperatures $\left(900-1150^{\circ} \mathrm{C}\right)$ existed inside the ferrite and fayalite phases, indicating that the reduction of iron was initiated in the monomer and exposed silicate aggregates, subsequently proceeding via solid diffusion. Intuitively, $\mathrm{Fe}$ in the silicate gradually reduced and disappeared, and the products with a small amount of iron replaced the original ferrite and fayalite, with the simultaneous observation and merging of metal particles; thus, the size of the metal particles increased.

Fig. 8 shows the optical microscopy images of the pellet reduced at different coal dosages. The merging of the metallic phase particles in the pellets became more common at a coal dosage of $25 \%$; under this condition, the size of the coarse particles was greater than $40 \mu \mathrm{m}$.

The optical microscopy images of the reduced pellet at different reduction times (Fig. 9) show that prolonging the reduction time promotes the merging of the metal particles and the reduction of iron silicate. This observation explains the results in Fig. 2(c).

The particle size of iron metal and the number and type of refractory silicate slag particles in the reduced pellets with or without calcium chloride differ (Fig. 10). Specifically, the particle size range of metallic iron was large, and some coarse metal particles were observed in the reduced pellet without the added calcium chloride; however, in the case where calcium chloride was added, a large amount of the liquid metal phase was generated and the particle size distribution of the metal phase was uniform, with a small number of coarse metal particles. In addition, hedenbergite was observed in the reduced pellet with calcium chloride. In summary, calcium chloride facilitated the diffusion and merging of metal iron particles. The mechanistic action of calcium chloride on the growth of metal particles is not clear and is beyond the scope of the present work.
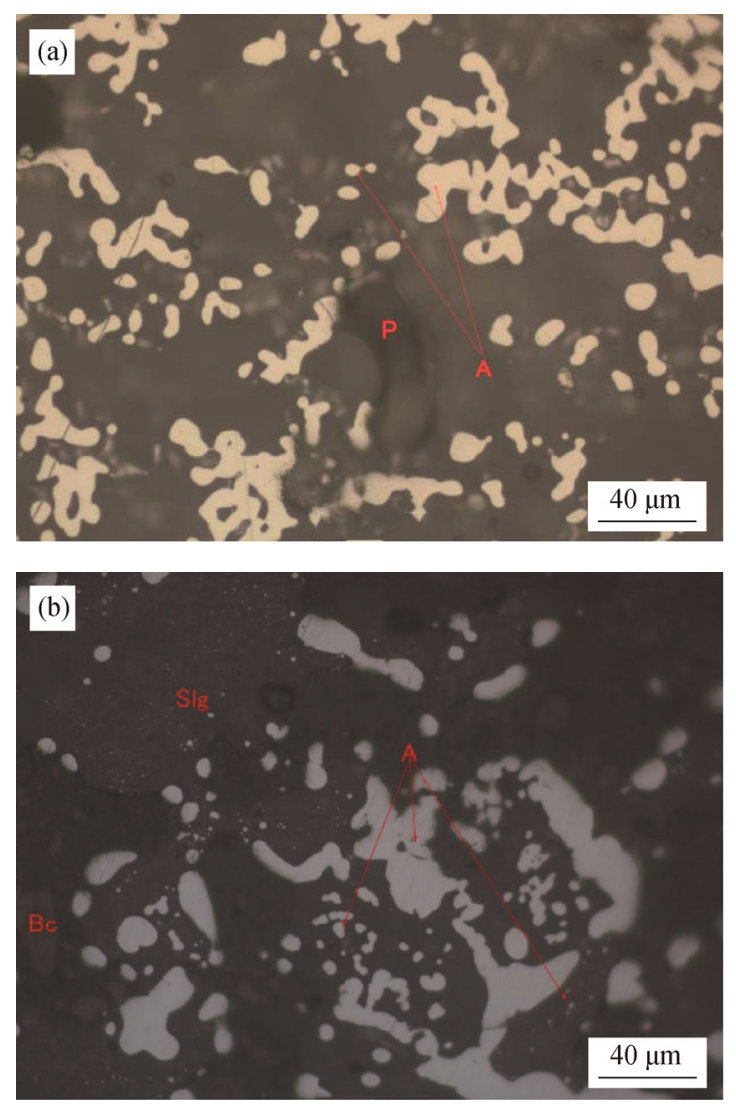

Fig. 8. Optical microscopy images of the reduced pellets at different coal dosages: (a) 15\%; (b) 25\%. A-metallic phase; Slg—slag; Bc—black charcoal; P—pore.

\subsubsection{Characterization of magnetic concentrate and tailing}

XRD and optical microscopic analyses were used to observe the magnetic concentrate generated under the optimum conditions, corresponding to the product obtained from magnetic separation. Figs. 11 and 12 show the corresponding results. The main phase of the concentrate is metallic iron (Fig. 11). In addition, small amounts of fayalite and magnesium aluminum silicate were observed in the concentrate. 

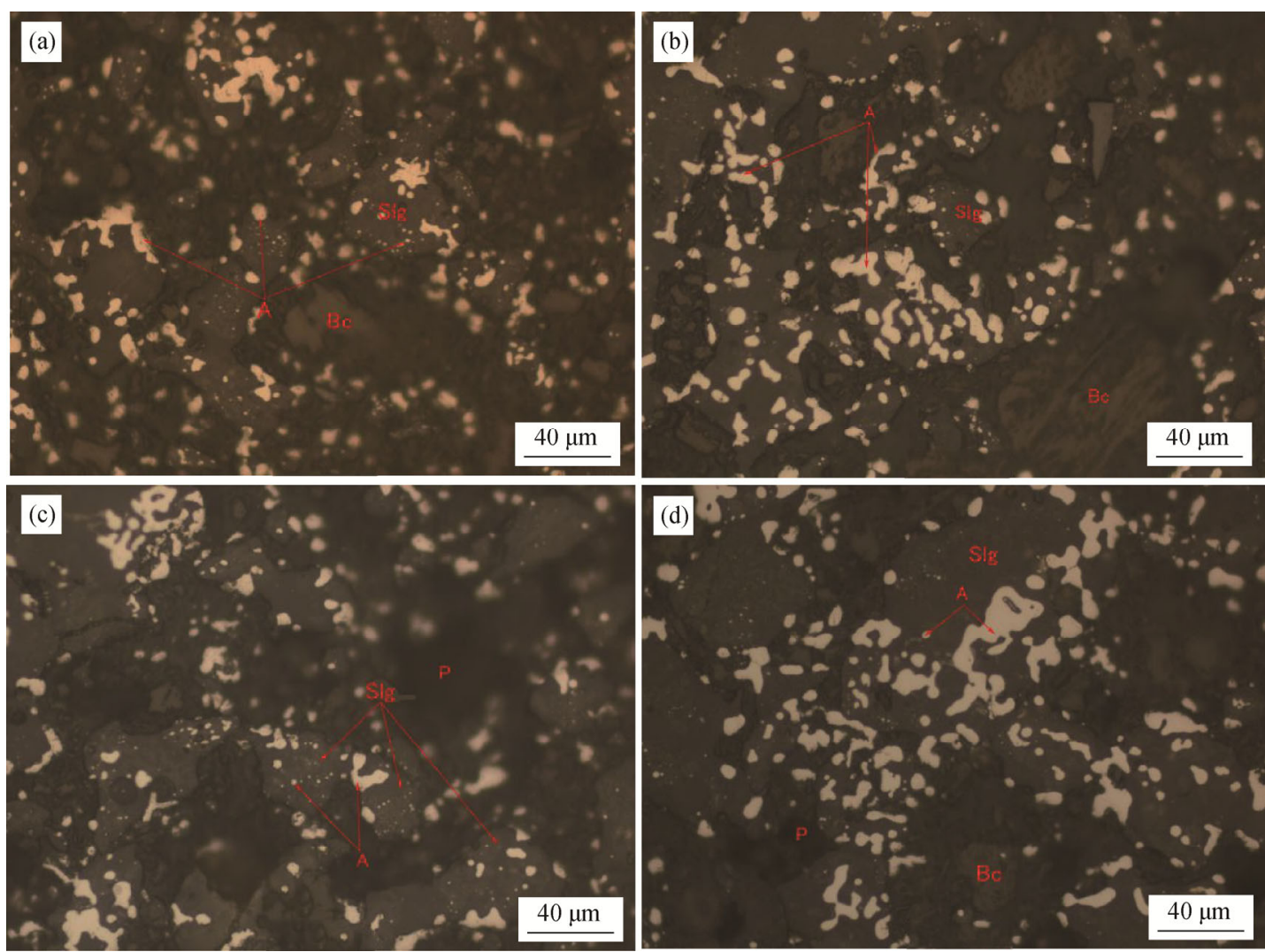

Fig. 9. Optical microscopy images of the reduced pellets at different reduction times: (a) $20 \mathrm{~min}$; (b) $40 \mathrm{~min}$; (c) $60 \mathrm{~min}$; (d) $90 \mathrm{~min}$. A—metallic phase; Slg—slag; Bc—black charcoal; $\mathrm{P}$ - pore.
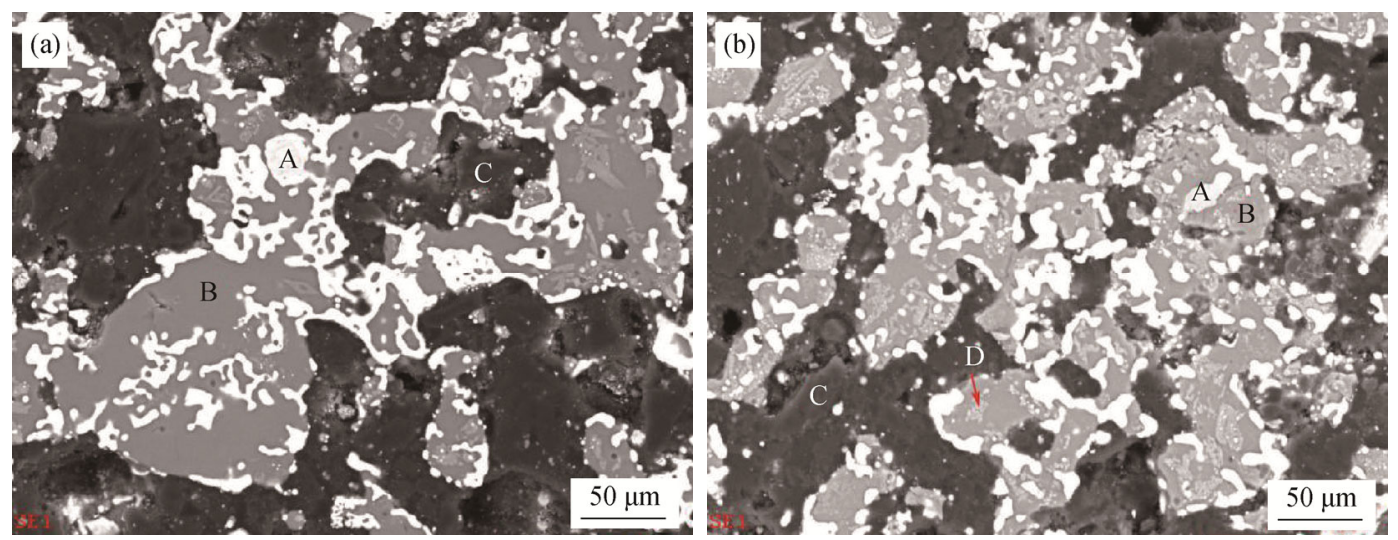

Fig. 10. SEM images of the reduced pellet at different calcium chloride dosages: (a) without calcium chloride; (b) $2.5 \%$ of calcium chloride. A—metallic phase; $\mathrm{B}$ — silicate with a low iron content; $\mathrm{C}$-black charcoal; $\mathrm{D}$ —hedenbergite.

The optical microscopy image of the magnetic concentrate differed from that of the reduced pellet. Specifically, because of the crushing during grinding, the metal phase in the concentrate was flattened, with a length greater than 100 $\mu \mathrm{m}$ and a width of 3-40 $\mu \mathrm{m}$. The presence of slag in the concentrate was mainly related to the fine metallic iron in the slag. Metallic iron was enriched during magnetic separa- tion. Because the metallic iron and the slag were wrapped around each other and because of the inevitable entrainment during magnetic separation, a small amount of the slag still remained in the concentrate (Fig. 12).

The width of the XRD diffraction peak indicates poor crystallinity. In addition, a small amount of metallic iron was found in the slag (Fig. 12), which was unavoidable. 
Clearly, the main loss of iron in the tailing was related to the incomplete reduction of fayalite.

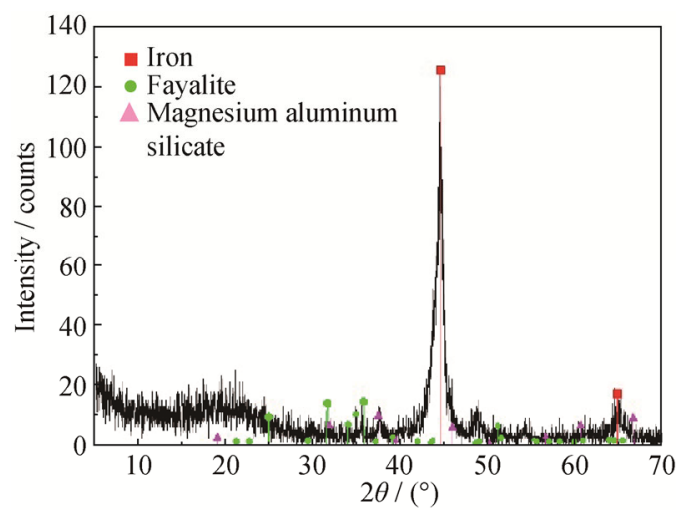

Fig. 11. XRD pattern of the magnetic concentrate.
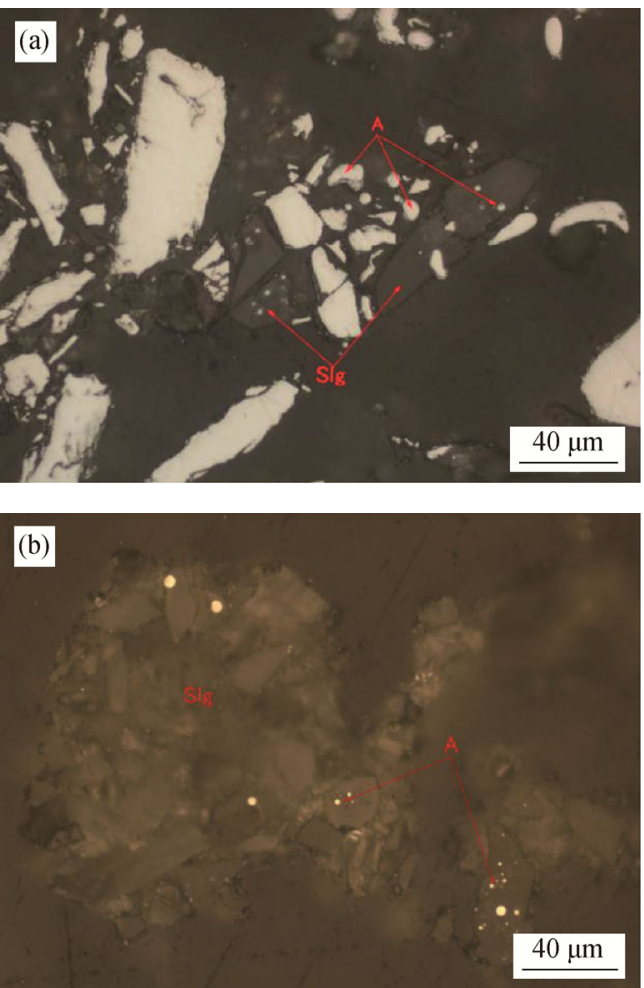

Fig. 12. Optical microscopy images: (a) magnetic concentrate; (b) tailing. A-metallic phase; Slg-slag.

\section{Conclusions}

(1) The optimal conditions for the recovery of iron included a reduction temperature of $1150^{\circ} \mathrm{C}$, a duration of $2 \mathrm{~h}$, a coal dosage of $25 \%$, a calcium chloride dosage of $2.5 \%$, a magnetic field intensity of $100 \mathrm{mT}$, and a grinding time of 1 min. Under such conditions, the iron grade of the magnetic concentrate was greater than $90 \%$, and the recovery ratio of iron was greater than $95 \%$.

(2) Mineralogical analysis suggested that ferrite and fayalite are the main constituent minerals in copper tailings and the main carriers of iron. A small amount of metallic iron was observed in the reduced pellet at $900^{\circ} \mathrm{C}$. Increasing temperature is beneficial for the reduction, merging, and growth of iron. The merging of the metal phase particles in pellets becomes more common at a coal dosage of $25 \%$. Prolonging the reduction time promotes the merging of metal particles and the reduction of iron silicate. Calcium chloride facilitates the diffusion and merging of metal iron particles. Fayalite and hedenbergite are the main phases in the tailing of the magnetic dressing. The main loss of iron in the tailing is related to the incomplete reduction of fayalite.

\section{Acknowledgements}

The authors are grateful to J. Tang who assisted with powder XRD, optical microscopy, and SEM-EDS analyses; C. Su for ICP-AES; and X. Xu for sulfur analyses. This work was financially supported by the National Natural Science Foundation of China (No. 51674026).

Open Access This article is distributed under the terms of the Creative Commons Attribution 4.0 International License (http://creativecommons.org/licenses/by/4.0/), which permits unrestricted use, distribution, and reproduction in any medium, provided you give appropriate credit to the original author(s) and the source, provide a link to the Creative Commons license, and indicate if changes were made.

\section{References}

[1] M.E. Schilesinger, M.J. King, K.C. Sole, and W.G. Davenport, Extractive Metallurgy of Copper, Elsevier, UK, 2011, p. 1.

[2] C.J. Shi, C. Meyer, and A. Behnood, Utilization of copper slag in cement and concrete, Resour. Conserv. Recycl., 52(2008), No. 10, p. 1115.

[3] B. Gorai, R.K. Jana, and Premchand, Characteristics and utilisation of copper slag-a review, Resour. Conserv. Recycl., 39(2003), No. 4, p. 299.

[4] M. Najimi and A.R. Pourkhorshidi, Properties of concrete containing copper slag wast, Mag. Concr. Res., 63(2011), No. 8, p. 605.

[5] M. Khanzndi and A. Behnood, Mechanical properties of high-strength concrete incorporating copper slag as coarse aggregate, Constr. Build. Mater., 23(2009), No. 6, p. 2183.

[6] K.S. Al-Jabri, M. Hisada, S.K. Al-Oraimi, and A.H. Al-Saidy, Copper slag as sand replacement for high performance con- 
crete, Cem. Concr. Compos., 31(2009), No. 7, p. 483.

[7] K. Kambham, S. Sangameswaran, S.R. Dater, and B. Kura, Copper slag: optimization of productivity and consumption for cleaner production in dry abrasive blasting, J. Cleaner Prod., 15(2007), No. 5, p. 465.

[8] M.E. Schlesinger, M.J. King, K.C. Sole, and W.G. Davenport, Extractive Metallurgy of Copper, Elsevier, UK, 2011, p. 415.

[9] S. Mostaghel, C. Samuelsson, and B. BjÖrkman, Influence of alumina on mineralogy and environmental properties of zinc-copper smelting slags, Int. J. Miner. Metall. Mater., 20(2013), No. 3, p. 234.

[10] R.R. Moskalyk and A.M. Alfantantazi, Review of copper pyrometallurgical practice: today and tomorrow, Miner. Eng., 16(2003), No. 10, p. 893.

[11] S. Vaisburd, A. Berner, D.G. Brandon, S. Kozhakhmetov, E. Kenzhaliyev, and R. Zhalelev, Slags and mattes in vanyukov's process for the extraction of copper, Metall. Mater. Trans. B, 33(2002), No. 4, p. 551.

[12] A. Sarrafi, B. Rahmati, H.R. Hassani, H.R. Hassani, and H.H.A. Shirazi, Recovery of copper from reverberatory furnace slag by flotation, Miner. Eng., 17(2004), No. 3, p. 457.

[13] F. Yin, P. Xing, Q. Li, C.Y. Wang, and Z. Wang, Magnetic separation-sulphuric acid leaching of $\mathrm{Cu}-\mathrm{Co}-\mathrm{Fe}$ matte obtained from copper converter slag for recovering $\mathrm{Cu}$ and $\mathrm{Co}$, Hydrometallurgy, 149(2014), p. 189.

[14] G. Tozsin, Inhibition of acid mine drainage and immobilization of heavy metals from copper tailings using a marble cutting waste, Int. J. Miner. Metall. Mater., 23(2016), No. 1, p. 1.

[15] M. Najimi and A.R. Pourkhorshidi, Properties of concrete containing copper slag waste, Mag. Concr. Res., 63(2011), No. 8, p. 605.

[16] A. Lowinska-Kluge, P. Piszora, J. Darul, T. Kantel, and P. Gambal, Characterization of chemical and physical parameters of post copper slag, Cent. Eur. J. Phys., 9(2011), No. 2, p. 380 .

[17] T. Van Long, J. Palacios, M. Sanches, T. Miki, Y. Sasaki, and M. Hino, Recovery of molybdenum from copper slag, Tetsu-To-Hagane, 98(2012), No. 2, p. 48.

[18] B. Kiyak, A. Özer, H.S. Altundoğan, M. Erdem, and F. Tümen, $\mathrm{Cr}(\mathrm{VI})$ reduction in aqueous solutions by using copper smelter slag, Waste Manage., 19(1999), No. 5, p. 333.

[19] L.N. Zhang, The Valuable Components of Selective Precipitation of Copper Slag [Dissertation], Northeastern University, Shenyang, 2005.

[20] L. Li, J.H. Hu, and H. Wang, Study on smelting reduction ironmaking of copper slag, Chin. J. Process Eng., 2011, No. 1, p. 65.

[21] L.P. Niu, J.Y. Liu, J.B. Song, and W.L. Xi, Study on reduction process of melting copper slag with natural gas, J. Mater. Metall., 15(2016), No. 3, p. 200.

[22] H.F. Yang, L.L. Jing, and C.G. Gang, Iron recovery from copper-slag with lignite-based direct reduction followed by magnetic separation, Chin. J. Nonferrous Met., 21(2011), No. 5, p. 1165.

[23] S. Wang, W. Ni, C.L. Wang, D.Z. Li, and H.Y. Wang, Study of deep reduction process for iron recovery from copper slag tailings, Met. Mine, 2014, No. 3, p. 156.

[24] K.Q. Li, S. Ping, H.Y. Wang, and W. Ni, Recovery of iron from copper slag by deep reduction and magnetic beneficiation, Int. J. Min. Metall. Mater., 20(2013), No. 11, p. 1035.

[25] W.R. Liu, X.H. Li, Q.Y. Hu, Z.X. Wang, K.Z. Gu, J.H. Li, and L.X. Zhang, Pretreatment study on chloridizing segregation and magnetic separation of low-grade nickel laterites, Trans. Nonferrous Met. Soc. China, 20(2010), Suppl. 1, p. s82.

[26] L.I. Barbosa, J.A. González, M. Del, and C. Ruiz., Extraction of lithium from $\beta$-spodumene using chlorination roasting with calcium chloride, Thermochim. Acta, 605(2015), p. 63. 